\title{
Clasp and dance: Mating mode promotes variable sexual size and shape dimorphism trajectories in crocodile newts (Caudata: Salamandridae)
}

\author{
Peter Pogoda ${ }^{1}$, Marcus Zuber ${ }^{2}$, Tilo Baumbach ${ }^{2}$, and Alexander Kupfer ${ }^{1}$ \\ ${ }^{1}$ Stuttgart State Museum of Natural History \\ ${ }^{2}$ Karlsruhe Institute of Technology
}

July 26, 2021

\begin{abstract}
Sexual dimorphism (SD) is a main source of intraspecific morphological variation, however sexual shape dimorphism (SShD) was long time neglected in evolutionary research. Especially in cold-blooded animal groups only subtle shape differences are expressed between males and females and the selective forces behind it are poorly understood. Crocodile newts of the genera Echinotriton and Tylototriton are highly polymorphic in their reproductive ecology and hence, are a highly suitable model system to investigate potential evolutionary forces leading to SShD differences. We applied 3D geometric morphometrics to the cranial and humerus morphology of nine species of crocodile newts to investigate patterns of SShD in relation to the different mating modes. Trajectories of shape differences between males and females differ in both, cranium and humerus but mating mode does explain differences in SShD trajectories between species only in cranial morphology. Nevertheless, cranial morphology shape differed between the amplecting and circle dancing species. Hence, other selective forces must act here. Variable interspecific allometric trajectories are a potential source of shape differences whereas these trajectories are quite stable for the sexes irrespective of the species.
\end{abstract}

Clasp and dance: Mating mode promotes variable sexual size and shape dimorphism trajectories in crocodile newts (Caudata: Salamandridae)

Peter Pogoda ${ }^{1,2, *}$, Marcus Zuber ${ }^{3,4}$, Tilo Baumbach ${ }^{3,4}$, Alexander Kupfer ${ }^{1,5}$

1 Department of Zoology, State Museum of Natural History Stuttgart, Rosenstein 1, 70191 Stuttgart, Germany

2 Comparative Zoology, Institute of Evolution and Ecology, Eberhard Karls University Tuebingen, Auf der Morgenstelle 28, 72076 Tuebingen, Germany

3 Institute for Photon Science and Synchrotron Radiation (IPS), Karlsruhe Institute of Technology (KIT), Hermann-von-Helmholtz-Platz 1, 76344 Eggenstein-Leopoldshafen, Germany

4 Laboratory for Applications of Synchrotron Radiation (LAS), Karlsruhe Institute of Technology (KIT), Kaiserstr. 12, 76131 Karlsruhe, Germany

${ }^{5}$ Institute of Zoology, University of Hohenheim, Garbenstr. 30, 70593 Stuttgart, Germany

* Corresponding author: Peter Pogoda, Department of Zoology, State Museum of Natural History Stuttgart, Rosenstein 1, 70191 Stuttgart, Germany, peter.pogoda@smns-bw.de 


\begin{abstract}
Sexual dimorphism (SD) is a main source of intraspecific morphological variation, however sexual shape dimorphism (SShD) was long time neglected in evolutionary research. Especially in cold-blooded animal groups only subtle shape differences are expressed between males and females and the selective forces behind it are poorly understood. Crocodile newts of the genera Echinotriton and Tylototriton are highly polymorphic in their reproductive ecology and hence, are a highly suitable model system to investigate potential evolutionary forces leading to SShD differences. We applied 3D geometric morphometrics to the cranial and humerus morphology of nine species of crocodile newts to investigate patterns of SShD in relation to the different mating modes. Trajectories of shape differences between males and females differ in both, cranium and humerus but mating mode does explain differences in SShD trajectories between species only in cranial morphology. Nevertheless, cranial morphology shape differed between the amplecting and circle dancing species. Hence, other selective forces must act here. Variable interspecific allometric trajectories are a potential source of shape differences whereas these trajectories are quite stable for the sexes irrespective of the species.
\end{abstract}

Key words: Tylototriton, geometric morphometrics,Echinotriton, reproductive biology, ecology, sexual selection

\title{
Cover letter
}

Dear chief-editors,

We are delighted to submit our manuscript entitled "Clasp and dance: Mating mode promotes variable sexual size and shape dimorphism trajectories in crocodile newts (Caudata: Salamandridae)" toEcology and Evolution, exclusively.

The knowledge about the evolutionary processes leading to dimorphic sexes is still somehow cryptic and not fully understood especially in cold-blooded animal groups which often express only subtle shape differences between males and females. The enigmatic crocodile newts of the genera Tylototriton and Echinotriton are on the one hand morphologically conservative, but on the other hand polymorphic in their reproductive behaviour and hence, represent a well-suited model system to investigate evolutionary forces leading to different patterns of sexual dimorphisms. We carried out a comparative approach on several species exhibiting different mating behaviours, by applying 3D geometric morphometrics to the cranium and humerus. Especially, the humerus is of interest as it plays a major role between the different mating modes. Our study reveals how the ecology of a species interacts with the expressed patterns of sexual shape dimorphism in these newts and add another important piece to the puzzle in understanding the evolution of sexual dimorphisms.

We are sure our work and the approach used herein is of interest to a broader audience of evolutionary biologists, ecologists and morphologists.

We look forward to hearing from you in the near future.

Yours sincerely,

Peter Pogoda, Marcus Zuber, Tilo Baumbach and Alexander Kupfer

\section{Introduction}

Sexual dimorphism (SD) subscribing marked differences between sexes such as in morphology is a common phenomenon in the animal kingdom (e.g., Fairbairn et al., 2007). Different theories try to explain the causal relationship between selection and morphology, namely i. fecundity (e.g., Kupfer et al., 2004), ii. sexual selection (Shine, 1979) and iii. ecological niche portioning (Hedrick \& Temeles, 1989, Shetty \& Shine, 2002). 
In context with body architecture, SD can be expressed as size dimorphism (SSD) or shape dimorphism (SShD) underlying different selection processes (e.g., Schwarzkopf, 2005, Kupfer, 2007, Pogoda \& Kupfer, 2018). While SSD is better studied and known in many vertebrates (e.g., Cox et al., 2007, Lindenfors et al., 2007), SShD needs much more attention as it substantial influence species ecology (e.g., Shetty \& Shine, 2002, Alcorn et al., 2013, Pogoda \& Kupfer, 2018, Pogoda et al., 2020).

To understand the processes leading to different morphologies between males and females, comparative studies are needed allowing conclusions from species ecology to its morphology. Amphibians are a vertebrate group with heavily female-biased SSD (e.g., Shine, 1979, Kupfer, 2007). Nevertheless, only approximately $61 \%$ of known salamander species exhibit female-biased SSD, while about $19 \%$ exhibit a male-biased SSD (Kupfer, 2007, Amat, 2019). Although less diverse in terms of species numbers, urodeles evolved various reproductive modes and behaviours including diverse life history strategies (Sparreboom, 2014, Kieren et al., 2018). As Salamandridae or true salamanders includes most of the variability in reproductive biology known from urodeles (Sparreboom, 2014, Frost, 2018), making the group well-suited for the investigation of SSD and SShD.

Pleurodeline newts, named Pleurodelini, comprise a diverse monophyletic group of salamandrid salamanders (e.g., Veith et al., 2018, Wang et al., 2018) thus, being important in the reconstruction and understanding of the evolutionary processes forming SD among Salamandridae (Pogoda \& Kupfer, 2018). Among Pleurodelini monophyletic crocodile newts evolved a variety of reproductive modes and strategies (Salvador \& GarcíaParís, 1999, Hernandez, 2016, Kieren et al., 2018). For mating either a ventral amplexus or a circular mating dance is performed either taking place in aquatic or terrestrial habitats. Also, female crocodile newts deposit egg clutches either in water or on land (Igawa et al., 2013, Phimmachak et al., 2015b, Pasmans et al., 2017, Gong et al., 2018, Hernandez, 2016). These differences in terms of mating and reproductive ecology can even be observed within one genus Tylototriton comprising most crocodile newt species. Some of the reproductive traits correlate with phylogeny e.g., oviposition site, while others do not e.g., mating mode. Nevertheless, both phylogeny and phylogenetic independent ecological traits leading to coevolution of similar cranial shapes among crocodile newts (Pogoda et al., 2020). So far, SD was rarely investigated in crocodile newts (Seglie et al., 2010, Phimmachak et al., 2015b). Many studies are regularly descriptive and limited to a few body measurements such as snout-vent length, cloacal size and some others (e.g., Khatiwada et al., 2015, Fei \& Ye, 2016, Hernandez \& Hou, 2018) often with low sample sizes. A variety of SSD and SShD patterns such as longer and wider trunks in females and longer limbs and crania in males are known in many other salamandrids (e.g., Malmgren \& Thollesson, 1999, Romano et al., 2009, Amat et al., 2015, Reinhard et al., 2015, Reinhard \& Kupfer, 2015, Altunışı, 2017). Consequently, it is likely that also a variety of dimorphic traits are undetected so far in crocodile newts. There is even less known about SD in the osteology of urodeles in general (Ivanović \& Kalezić, 2012, Pogoda \& Kupfer, 2018). Researchers just started exploring this field of morphology research accessed mainly by modern non-invasive CT technology (Broeckhoven \& du Plessis, 2018). In a terrestrial salamandrid salamander, it was shown that the same patterns of SSD can be detected in the osteology as in the external morphology (Pogoda \& Kupfer, 2018). Further, excluding soft tissue leads to an enormous increase of morphological structures which can be used in studying especially SShD otherwise covered. In ventral amplecting Pleurodeles, the sister taxon to the crocodile newt genera Tylototriton and Echinotriton, differentially shaped humeri between sexes are known for long time (e.g., Herre, 1952). The common ancestry of ribbed and crocodile newts and the interspecifically different reproductive strategies may imply variable SD patterns tightly linked to ecology. Understanding SSD and SShD patterns in context with phylogeny and ecology will aid understanding the evolutionary biology of salamanders. Thus, rather then just providing intersexual comparisons of measurements or shape data, these must be linked to other traits of the investigates system in order to be able to reveal potential selection sources leading to observed morphological differences.

The aim of our study was to investigate SD in crocodile newts, linking patterns to the different reproductive ecologies of the species. Our focus was laid on the cranium and fore limb morphology. Male cranial morphology was different among amplectant and dancing species (Pogoda et al., 2020). Thus, we assumed different interspecific patterns of SShD of crocodile newt cranial morphology applying different mating modes. Fore 
limb morphology is of special interest as the fore limb likely experiences different mechanical needs when a ventral amplexus is applied or not. We hypothesize that species which apply an amplexus during mating have a more pronounced SSD of their fore limbs than species mating without physical contact and that the different mating patterns lead also to differences in SShD between these reproductive groups. We used $\mu \mathrm{CT}$ scans of crania and humeri of crocodile newts and employed 3D geometric morphometrics (GM) to test our hypotheses.

\section{Material \& Methods}

For resolving SSD and SShD, we investigated 227 crocodile newt specimens of the genera Echinotriton and Tylototriton housed in natural history collections (Supplementary Table S1) including the following: E. andersoni from Okinawa Island, Tylototriton asperrimus, T. himalayanus, T. kweichowensis, T. shanjing, T. shanorum, T. taliangensis, T.uyenoi and T. verrucosus. The selected species represent all major clades of crocodile newts comprising the different mating modes i.e., showing a circle dance or applying an amplexus (Pogoda et al., 2020). Following species are generally thought to be circle dancers: E. andersoni, T. asperrimus, T. kweichowensis, T. shanjing, while the others are regularly observed to apply an amplexus. Tylototriton asperrimus represent the only member of the subgenus Yaotriton with a sufficient sample size of both sexes whereas unfortunately not enough female specimens of other species were available in natural history collections due to a heavy male biased field sampling during the breeding season. To access osteology for SD analyses, specimens were $\mu \mathrm{CT}$-scanned. CT-scans were carried out either with a Bruker SkyScan1272 with the software NRecon (Bruker CT) for reconstructions or within the X-ray imaging laboratory at the Institute for Photon Science and Synchrotron Radiation, Karlsruhe Institute of Technology (KIT) employing a microfocus x-ray tube (XWT-225, X-RAY WorX, Garbsen, Germany) and a flat panel detector (XRD 1621 CN14 ES, PerkinElmer, Waltham, USA) in combination with a custom designed mechanical sample manipulator. For the CT scans made at KIT, Octopus 8.6 (Inside Matters, Gent, Belgium) was used to perform the tomographic reconstruction. The scan resolution was either 20.1 (SkyScan) or $21.3 \mu \mathrm{m}$ (KIT-custom build scanner).

To catch the entire shape variation of the cranium 45 three-dimensional (3D) landmarks were digitized and for the analysis of the humerus shape six fixed landmarks and 50 semi-landmarks in three curves were digitized (Fig.1). Prior to landmark digitization, potential error in setting landmarks was validated by digitizing one specimen five times and five additional specimens of the same species to compare consistent placement by Procrustes distance of the respective mean shapes. Landmark digitization was carried out by one author with the software Checkpoint v.2019.03.04.1102 (Stratovan Ltd.). Geometric morphometrics was performed in $\mathrm{R}$ version 3.6.3 (R Development Core Team, 2019) using the packages geomorph v.3.2.1, RRPP v. 0.5.2 and Morpho 2.8 (Schlager, 2017, Collyer \& Adams, 2018, Adams et al., 2019). Complete landmark configurations are a prerequisite for GM analyses. Hence, missing landmarks (due to anomalies or injuries) were first estimated by thin plate spline approach implemented in the function 'estimate.missing' (Gunz et al., 2009). Semi-landmarks in the humerus dataset were equally spaced along the digitized curve. Variation due to location, rotation and scale was removed by a generalized Procrustes alignment (GPA) using the function 'gpagen' (Rohlf \& Slice, 1990). In the humeri dataset, semi-landmarks were simultaneously slided using minimized bending energy (Bookstein, 1997a, Perez et al., 2006). As asymmetry was not in the scope of this study, bilateral landmarks in cranial landmark configuration were symmetrized by averaging left and right landmark pairs. Skulls and humeri were analysed further in the same approach. A principal component analysis (PCA) on Procrustes coordinates was performed and plotted to investigate general shape variation. To account for size, we used logarithm of centroid size (CS), which represents a measure of size in GM (Bookstein, 1997b, Zelditch et al., 2012).

A full factorial model design including species and mating mode was precluded by the model system as each species comprises only a single mating mode. Thus, several Procrustes ANOVAs had to be performed to investigate all potential sources of morphological variation. First, a Procrustes ANOVA as implemented 
in the function 'procD.lm' with size, species and sex including all interactions was performed. Allometry between sexes was not different, indicated by non-significant interaction between sex and CS. Thus, we explored allometric shape change by another Procrustes ANOVA including CS and sex only. To test whether mating mode affects the pattern of SD, we first ran a model design including only sex, mating mode and its interaction, and second a model including these factors plus CS as covariate. To explore different patterns of SShD, we performed a trajectory analysis to visualize shape change directions between species and performed a group mean prediction with 95\%-confidence intervals for males and females in each species, implemented in the function 'predict.lm.rrpp' in the RRPP package. Sexual size dimorphism patterns between species and mating modes were estimated by a Procrustes ANOVA of species and sex on CS and, in a second one, sex and mating mode as variables. The function 'pairwise' was used to reveal which groups were different. According to the model, a grouping variable of sex with species or mating mode was used. Significance testing was performed using Residual Randomization by 10.000 random permutations (Collyer et al., 2015, Collyer \& Adams, 2018). Shape changes were visualized as TPS-grids by warping the mean shape by thin-plate spline approach with the function 'plotRefToTarget'.

\section{Results}

\section{Shape and size}

The first two principal component (PC) axes of humerus shape explained 34.5\% (PC1) and 13.7\% (PC2) of the observed shape variation (Fig.2).Echinotriton andersoni occupied a slightly different morphospace than Tylototriton, although there was some overlap especially with T. uyenoi and T. kweichowensis . Generally shape changes on the first PC corresponded to humerus thickness, representing thick humeri for negative PC1-scores and thin humeri for positive PC1-scores. The second PC corresponded to the thickness of the middle part of the humerus and the orientation of the Crista dorsalis humeri. According to that, Echinotriton exhibits more robust humerus shape compared to Tylototriton, T. taliangensis exhibiting the most gracile humerus. PC1 explained $20.1 \%$ and PC2 $11.6 \%$ of the observed shape variation (Fig.3) of the PCA of cranial shape. Echinotriton was well separated from all other species of the genus Tylototriton, but T. asperrimus showed the highest similarity to Echinotriton. Among Tylototritonspp., T. kweichowensis occupied the most distinct morphospace (Fig.3). Echinotriton -skull shape (positive PC1 scores) showed a robust skull with a strong maxillary connection to the quadrate and pterygoid. The snout was more pointed and with lower and anteriorly ranging nasals than in all Tylototriton. The second PC axis corresponds to the height of the fronto-squamosal arch in relation to the skull roof, the posterior extent of the squamosal and the occiput width.

Procrustes ANOVA revealed a strong allometric effect both in humerus and cranial shape (Tab.1). The allometric trajectories differed interspecifically (Fig.4) but not intersexually (Fig.5), indicated by a significant interaction of size and species but not size and sex (Tab.1). In allometric trajectories of the humerus, $T$. uyenoi and T. shanorum exhibited a different direction (Fig.4a) while in cranial shape, especially T. asperrimus showed a different pattern (Fig.4b). Accounting for sexual allometry only, generally large specimens exhibited a thinner humerus (Fig.5a) whereas in the cranium the dorso-lateral ridge became more elaborate and the connection of the maxillary with the pterygoid and quadrate turned more pronounced and the quadrate shifted more posteriorly (Fig.5b).

\section{Sexual dimorphism}

The Procrustes ANOVA revealed different interspecific patterns of sexual dimorphism, indicated by the significant interaction of species and sex (Tab.1). In order to test our hypothesis that the mating mode might explain different shapes, we carried out additional Procrustes ANOVAs on shape including mating mode as explanatory variable. The mating mode explained a significant amount of variation, with and without $\log (\mathrm{CS})$ as covariate, in the humerus and cranium (Tab.2). In general the species applying a circle 
dance had more robust and thicker humeri including an elaborated crista dorsalis and a higher crista ventralis compared to species employing a ventral amplexus (Fig.6). The cranium of circle dancers was wider at its occiput, exhibited a shorter frontal arch, less connection between the maxillary bone and the quadrate and pterygoid, a higher snout tip, longer vomerine tooth rows and more distal internal nares. The interaction term of mating mode with sex was significant in cranial shape when accounting for size as covariate (Tab.2 b), indicating different SShD-trajectories between the two different mating modes among identical size classes (Tab.2 b, d). We found no indication for different SShD-trajectories between mating modes in humerus shape.

As the analysis indicated different SD-trajectories, we performed a trajectory analysis with sex as grouping factor to figure out and illustrate shape changes in different trajectories across male and females between species (Fig.7, 8). Echinotriton andersoni did not differ markedly from Tylototriton spp. In the latter, cranial SD-trajectories showed contrary directions between some species (Fig.8). Pairwise species-comparison revealed only one pair of species (T. asperrimus : T. taliangensis) with an alpha-level below $5 \%$ and six species pairs below $10 \%$ for humerus SShD patterns and two species pairs below $5 \%$ and $10 \%$ (T.himalayanus : T. kweichowensisand T. shanjing : T. verrucosus ), respectively in SShD patterns of cranium shape (Appendix Tab. A2). To illustrate the different male to female SD-trajectories we plotted TPS-grids for amplecting T. himalayanus and circle dancing T. kweichowensis, both species deviating strongly in SDtrajectories (Fig.7, 8). In T. himalayanus, the humerus turned thinner in the middle part while the distal end was more twisted in females. Further, the crista ventralis was slightly more pronounced in females. In T. kweichowensis especially the crista dorsalis appeared more elaborate in females (Fig.7). Male to female shape changes in cranium morphology of $T$. himalayanus included an elaborated squamosal bony ridge, a posterior shift of the quadrate, a stronger connection of the maxillary with quadrate and pterygoid, lower nostrils and a shorter frontal arch. In T. kweichowensis cranial shape changes between sexes were much less pronounced and comprised a posterior shift of the quadrate and a slightly posteriorly shift of the palatal fissure between the vomers. Shape changes from the mean shape to male and female shape, respectively, were similar in the humerus, but differed between males and females in their extent, whereas cranial shape changes to the mean deviated between sexes of T. himalayanus but not in T. kweichowensis (Fig.9).

Procrustes ANOVA on humerus and cranium $\log (\mathrm{CS})$ of species and sex revealed interspecific but also intersexual differences in size (Tab.3 a, b). Further, SSD differed between species indicated by a significant interaction of species and sex (Tab.3 a, b) . Analysis of the effect of mating mode on size yielded no general size differences in the humerus between dancing and amplecting species but the interaction of sex and mating mode was close to significance level (Tab.3 c) which would indicate differences of SSD patterns between mating modes. Cranial size and SSD-patterns do differ between mating modes (Tab.3 d). Pairwise comparisons showed that male and females of amplecting species differ $(\mathrm{Z}=2.04, \mathrm{p}=0.019)$ in cranial size while this is not the case for circle dancers $(\mathrm{Z}=-1.76, \mathrm{p}=0.96)$. For the humerus, the same pattern applies but the effect size between amplecting males and females is only close to significance $(\mathrm{Z}=1.53, \mathrm{p}=0.066)$.

\section{Discussion}

We applied 3D geometric morphometrics on humerus and cranial osteology in crocodile newts, a group of largely understudied Asian salamandrid salamanders with polymorphic reproductive strategies, in order to reveal patterns of SD and how it is linked to the different mating behaviours. Our study does add new insights into the evolutionary forces leading to morphological differences between the sexes in urodeles. We confirmed our hypothesis that the different reproductive ecologies of crocodile newts lead (at least partly) to different patterns of SSD and SShD, as well as evolutionary trajectories of SD.

In salamandrids, it has been shown that allometric trajectories differ between taxonomic units allowing higher flexibility for shape evolution (Ivanović et al., 2007, Cvijanović et al., 2014, Ivanović \& Arntzen, 2017). Even within populations of a species, differences in allometries can be traced (Ivanović \& Kalezić, 2012). Most of the pleurodeline newt species showed similar allometric trajectories but some were able to 
evolve into a different direction. Although there was a high flexibility in allometries across different genera, similar allometric shape changes were observed throughout the pterygoid, quadratum and the decrease of the occipital region (Ivanović et al., 2012). Apparently the anterior skull shape was therefore more flexible. We found similar allometric trajectories between males and females in all species. In some populations of selected European newts, allometries differ between males and females (Ivanović et al., 2008) whereas in the most basal true salamander this is not the case (Pogoda et al., 2020). In general put on record, if selection acts on size in one sex, this can lead to shape differences due to allometric shape changes during growth (Ivanović \& Kalezić, 2012, Pogoda \& Kupfer, 2020). Complex interactions of different allometric trajectories between species and sexes make it complicated to pinpoint individual selective mechanisms. The different allometric trajectories between species likely lead at least partly to differences in shape as well as size differences in cranium and humerus occur in the different newt species. Thus, SShD-patterns can vary based on the allometric shape changes and the degree of SSD in a species. Further, some body parts in urodeles are rather less strongly ossified right after metamorphosis e.g., including the cranium, metacarpals and -tarsals but they ossify during ontogenetic growth. This could explain further shape variation in larger crania. Crocodile newts exhibit elaborated bony ridges and ornamentation on the cranial skeleton which may increase due to ongoing ossification during aging and growth, leading to more elaborated squamosal bony ridge at the posterior part. Increasing connection with size of the maxillary with the quadratum and pterygoid can likely be attributed also to the ongoing ossification during life.

Sexual shape dimorphisms in the cranium of other newts and salamanders comprise differences in vomer length, quadrate position, occipital region size, skull width and snout shape (Ivanović et al., 2008, Ivanović \& Kalezić, 2012, Alarcón-Rios et al., 2017, Pogoda et al., 2020). These shape changes were also present in crocodile newts, but they additionally differ in the extent of the squamosal bone. Different shape changes from males to females between populations were already indicated in other salamandrids like Lissotriton (Ivanović \& Kalezić, 2012), Ichthyosaura (Ivanović et al., 2009),Salamandra (Alarcón-Rios et al., 2017) and Salamandrina(Romano et al., 2009, Pogoda \& Kupfer, 2020). Different ecological selective forces each population of a species endures at its specific site, likely play a major role on the maintenance of subtle shape differences between species (Kalezić et al., 1992, Schäuble, 2004, Angelini et al., 2015). Crocodile newts inhabit a large distribution area from Nepal to Japan, including a variety of habitats from lowland rainforest to temperate, mountainous grasslands (Hernandez, 2016, Wang et al., 2018) forcing specific adaptations to those contrasting environments. On the other hand, this group of salamanders showed high conservatism in their macro-ecological differentiation (Hernandez et al., 2018) likely leading to little shape differentiation between species as well (Pogoda et al., 2020).

Sexual selection and sex roles during reproduction are a main force forming body shapes (see Darwin, 1871, Fairbairn et al., 2007). Previously, we found already that the mating mode partly explains shape variation in crocodile newts (Pogoda et al., 2020). While the mating mode is explaining the different SSD and SShDtrajectories of cranial morphology between species, it does not apply to the humerus, although they differ in shape between mating modes. As both sexes of amplecting species respond differently in cranial shape changes if referenced accordingly to the mean cranial shape but not in the humerus (Fig.9) differences of SD-trajectories of the cranium but not humerus morphology might be explained. Further, as the cranium is much more complex build it provides more possibilities for shape variation than the humerus does. Only amplecting species exhibit SSD in the body parts investigated herein. Often it is tried to explain cranial shape differences with differences in food niches (Shine, 1989, Shetty \& Shine, 2002, Ivanović \& Kalezić, 2012, Reinhard \& Kupfer, 2015) however our knowledge on food niche differences in salamanders is incomplete and a definite association of cranial shape differences with food niches is yet untested. No intersexual differences in food allocation were found in T. podichthys, the only studied crocodile newt in terms of trophic ecology (Phimmachak et al., 2015b). Size differences and slender humeri shape likely facilitate clasping (compare to Pleurodeles ) while more robust and ossified fore limbs provide better standing during circular dancing. This is contradictory to patterns found in European newts also applying a stereotypic courtship behaviour. Among European newts males regularly bear longer fore limbs (e.g., Malmgren \& Thollesson, 1999, Çiçek et al., 2011, Reinhard \& Kupfer, 2015). We demonstrated that different selective forces are acting differently 
on the crocodile newt taxa inducing interspecifically different allometric trajectories while the trajectories were constant between the sexes. We are aware that our sample size of some of the studied species and/or sex was relatively small, mainly attributable to the overwhelming male bias of crocodile newts housed in natural history collections sometimes with a male/female ratio of about 30/1 but GM was proved in being well capable of revealing even quite subtle shape differences (e.g., Blanco \& Godfrey, 2006, Abdel-Rahman et al., 2009, Arendt, 2010, Ivanović \& Kalezić, 2012, Pogoda et al., 2020)

We conclude that morphological adaptations between species take place in correlation with and probably adaptation to their occupied environments which include large variation from the tropics to temperate climate zones while the selective forces stay more or less constant in the entire group as sex roles do not diverge, although some aspects of reproduction and courtship adapted. The interaction of variable allometric trajectories of species and sexes might partly explain the interspecific differences in SD patterns observed. Additionally, ecological parameters might influence strength and direction of SD across populations. The mating mode is to some degree an explanatory variable of the interspecific cranial shape variation in the SDtrajectories. The humerus differed with mating mode but other selective forces shape SD-trajectories of this specific body part. However, to understand evolutionary processes future studies especially on the ecology of the enigmatic crocodile newts are needed. Numerous species were just recently identified based on molecular data leading to an enormous increase in species numbers over the last decade (Stuart et al., 2010, Shen et al., 2012, Nishikawa et al., 2013a, Nishikawa et al., 2013b, Hou et al., 2014, Nishikawa et al., 2014, Yang et al., 2014, Khatiwada et al., 2015, Le et al., 2015, Phimmachak et al., 2015a, Qian et al., 2017, Grismer et al., 2018, Grismer et al., 2019, Zaw et al., 2019, Bernardes et al., 2020, Pomchote et al., 2020, Poyarkov et al., 2021). However morphological distinct characters are hard to identify and often appear somehow descriptive summarising differences of particular body part proportions based on a few specimens without any accounting for SD. Unfortunately no information on ecology from the many recently described species is available and observations in captivity are often based on individuals of uncertain genetic identity. It will become more crucial to focus more on the intraspecific morphological differences applying an integrative approach for future taxonomic research on crocodile newts. Especially the subgenus Yaotritonincludes genetically distinct lineages not accessed accurately so far (e.g., Wang et al., 2018, Bernardes et al., 2020). Future research has to take into account larger taxonomic units with broader ecological niches to resolve evolutionary processes and mechanisms of SD on a larger scale.

\section{References}

Abdel-Rahman, E. H., Taylor, P. J., Contrafatto, G., Lamb, J. M., Bloomer, P. \& Chimimba, C. T. 2009. Geometric craniometric analysis of sexual dimorphism and ontogenetic variation: A case study based on two geographically disparate species, Aethomys ineptus from southern Africa and Arvicanthis niloticus from Sudan (Rodentia: Muridae). Mammalian Biology,74, 361-373.

Adams, D. C., Collyer, M. L. \& Kaliontzopoulou, A. 2019. Geomorph: Software for geometric morphometric analyses. $R$ package version 3.1.0 [Online]. Available: https://cran.r-project.org/package=geomorph [Accessed 01.03.2020].

Alarcón-Rios, L., Velo-Anton, G. \& Kaliontzopoulou, A. 2017. A non-invasive geometric morphometrics method for exploring variation in dorsal head shape in urodeles: sexual dimorphism and geographic variation in Salamandra salamandra .Journal of Morphology, 278, 475-485. https://doi.org/10.1002/jmor.20643

Alcorn, M. A., Deitloff, J., Graham, S. P. \& Timpe, E. K. 2013. Sexual dimorphism in head shape, relative head width, and body size of Eurycea aquatica and Eurycea cirrigera . Journal of Herpetology, 47, 321-327.

Altunısık, A. 2017. Sexual size and shape dimorphism in the Near Eastern fire salamander, Salamandra infraimmaculata (Caudata: Salamandridae). Animal Biology,67, 29-40. https://doi.org/10.1163/1570756300002519 
Amat, F. 2019. Patterns and allometries of sexual size dimorphism in salamanders and the rejection of Rensch's Rule. Salamandra, 55, 145-150.

Amat, F., Oromí, N., Sanuy, D. \& Carranza, S. 2015. Sexual dimorphism and age structure of the Montseny newt (Calotriton arnoldi ). Amphibia-Reptilia, 36,245-252.

Angelini, C., Sotgiu, G., Tessa, G., Bielby, J., Doglio, S., Favelli, M., Trenton, W., Garner, J., Gazzaniga, E. \& Giacoma, C. 2015. Environmentally determined juvenile growth rates dictate the degree of sexual size dimorphism in the Sardinian brook newt. Evolutionary Ecology, 29, 169-184.

Arendt, J. 2010. Morphological correlates of sprint swimming speed in five species of spadefoot toad tadpoles: comparison of morphometric methods. Journal of Morphology, 271, 1044-1052. https://doi.org/10.1002/jmor.10851

Bernardes, M., Le, M. D., Nguyen, T. Q., Pham, C. T., Pham, A. V., Nguyen, T. T., Rödder, D., Bonkowski, M. \& Ziegler, T. 2020. Integrative taxonomy reveals three new taxa within the Tylototriton asperrimus complex (Caudata, Salamandridae) from Vietnam. ZooKeys, 935, 121-164.

Blanco, M. \& Godfrey, L. 2006. Craniofacial sexual dimorphism in Alouatta palliata, the mantled howling monkey. Journal of Zoology, 270, 268-276.

Bookstein, F. L. 1997a. Landmark methods for forms without landmarks: morphometrics of group differences in outline shape. Medical Image Analysis, 1, 225-243.

Bookstein, F. L. 1997b. Morphometric tools for landmark data: geometry and biology, p.456 Cambridge, Cambridge University Press.

Broeckhoven, C. \& Du Plessis, A. 2018. X-ray microtomography in herpetological research: a review.Amphibia-Reptilia, 39, 377-401. https://doi.org/10.1163/15685381-20181102

Çiçek, K., Ayaz, D. \& Bayrakçı, Y. 2011. Morphology of the Northern Banded Newt, Ommatotriton ophryticus (Berthold, 1846)(Caudata: Salamandridae) in Uludağ (Bursa, Turkey).Herpetol Notes, 4, 161-165.

Collyer, M. L. \& Adams, D. C. 2018. RRPP: An r package for fitting linear models to high-dimensional data using residual randomization. Methods in Ecology and Evolution,9, 1772-1779.

Collyer, M. L., Sekora, D. J. \& Adams, D. C. 2015. A method for analysis of phenotypic change for phenotypes described by high-dimensional data. Heredity,115, 357-365. https://doi.org/10.1038/hdy.2014.75

Cox, R. M., Butler, M. A. \& John-Alder, H. B. 2007. The evolution of sexual size dimorphism in reptiles. In: Fairbairn, D. J., Blanckenhorn, W. U. \& Székely, T. (eds.) Sex, size and gender roles: evolutionary studies of sexual size dimorphism. Oxford: Oxford University Press.

Cvijanović, M., Ivanović, A., Kalezić, M. L. \& Zelditch, M. L. 2014. The ontogenetic origins of skull shape disparity in the Triturus cristatus group. Evolution \& Development, 16, 306-317. https://doi.org/10.1111/ede.12093

Darwin, C. 1871. The descent of man and selection in relation to sex, p.406, London, John Murray.

Fairbairn, D. J., Blanckenhorn, W. U. \& Székely, T. 2007. Sex, size and gender roles: evolutionary studies of sexual size dimorphism, p.266, Oxford, Oxford University Press.

Fei, L. \& Ye, C. 2016.Amphibians of China - Volume I, p.749, Beijing, Science Press.

Frost, D. R. 2018. Amphibian Species of the World: an Online Reference. Version 6.0 [Online]. Available: http://research.amnh.org/herpetology/amphibia/index.html [Accessed 29.07.2020].

Gong, Y., Shu, G., Huang, F., He, L., Li, C. \& Xie, F. 2018. Courtship behaviour and male sexual competition of the Taliang crocodile newt, Liangshantriton taliangensis .Amphibia-Reptilia, 39, 275-288. https://doi.org/10.1163/15685381-17000136 
Grismer, L. L., Wood, P. L., Quah, E. S., Thura, M. K., Espinoza, R. E. \& Murdoch, M. L. 2019. A new species of crocodile newt Tylototriton (Caudata: Salamandridae) from northern Myanmar (Burma). Journal of Natural History,53, 475-495.

Grismer, L. L., Wood, P. L., Quah, E. S. H., Thura, M. K., Espinoza, R. E., Grismer, M. S., Murdoch, M. L. \& Lin, A. 2018. A new species of Crocodile Newt Tylototriton(Caudata: Salamandridae) from Shan State, Myanmar (Burma).Zootaxa, 4500, 553-573. https://doi.org/10.11646/zootaxa.4500.4.5

Gunz, P., Mitteroecker, P., Neubauer, S., Weber, G. W. \& Bookstein, F. L. 2009. Principles for the virtual reconstruction of hominin crania. Journal of Human Evolution,1, 48-62. https://doi.org/10.1016/j.jhevol.2009.04.004

Hedrick, A. V. \& Temeles, E. J. 1989. The evolution of sexual dimorphism in animals: hypotheses and tests. Trends in Ecology \& Evolution, 4, 136-138.

Hernandez, A. 2016. Crocodile Newts - The Primitive Salamandridae of Asia (Genera Echinotriton and Tylototriton), p.415, Frankfurt am Main, Chimaira.

Hernandez, A., Escoriza, D. \& Hou, M. 2018. Patterns of niche diversification in south-east Asian crocodile newts. Zoologischer Anzeiger, 276, 86-93. https://doi.org/10.1016/j.jcz.2018.06.001

Hernandez, A. \& Hou, M. 2018. Natural history and biology of the Tiannan Crocodile Newt, Tylototriton yangi (Urodela: Salamandridae) at Gejiu, Yunnan province, China with its conservation implications. Nature Conservation Research, 3, 277-281. https://doi.org/10.24189/ncr.2018.018

Herre, W. 1952. Beiträge zur Kenntnis des Sexualdimorphismus einiger Salamandriden. Zoologischer Anzeiger, 148, 215-231.

Hou, M., Wu, Y., Yang, K., Zheng, S., Yuan, Z. \& Li, P. 2014. A missing geographic link in the distribution of the genus Echinotriton (Caudata: Salamandridae) with description of a new species from southern China. Zootaxa,3895, 89-102. https://doi.org/10.11646/zootaxa.3895.1.5

Igawa, T., Sugawara, H., Tado, M., Nishitani, T., Kurabayashi, A., Islam, M. M., Oumi, S., Katsuren, S., Fujii, T. \& Sumida, M. 2013. An Attempt at Captive Breeding of the Endangered Newt Echinotriton andersoni, from the Central Ryukyus in Japan. Animals, 3, 680-692.

Ivanović, A. \& Arntzen, J. W. 2017. Evolution of skull shape in the family Salamandridae (Amphibia: Caudata). Journal of Anatomy, 232, 1-12. https://doi.org/10.1111/joa.12759

Ivanović, A., Džukić, G. \& Kalezić, M. L. 2012. A phenotypic point of view of the adaptive radiation of crested newts (Triturus cristatus superspecies, Caudata, Amphibia). International journal of evolutionary biology,2012, 740605. https://doi.org/10.1155/2012/740605

Ivanović, A. \& Kalezić, M. L. 2012. Sexual dimorphism in the skull geometry of newt species ofIchthyosaura, Triturus and Lissotriton (Salamandridae, Caudata, Amphibia). Zoomorphology, 131, 69-78.

Ivanović, A., Sotiropoulos, K., Džukić, G. \& Kalezić, M. L. 2009. Skull size and shape variation versus molecular phylogeny: a case study of alpine newts (Mesotriton alpestris, Salamandridae) from the Balkan Peninsula.Zoomorphology, 128, 157-167.

Ivanović, A., Sotiropoulos, K., Furtula, M., Džukić, G. \& Kalezić, M. L. 2008. Sexual size and shape evolution in European newts (Amphibia: Caudata: Salamandridae) on the Balkan peninsula. Journal of Zoological Systematics and Evolutionary Research, 46, 381-387.

Ivanović, A., Vukov, T. D., Džukić, G., Tomašević, N. \& Kalezić, M. L. 2007. Ontogeny of skull size and shape changes within a framework of biphasic lifestyle: a case study in six Triturus species (Amphibia, Salamandridae).Zoomorphology, 126, 173-183. 
Kalezić, M. L., Crnobrnja, J., Dorovic, A. \& Džukić, G. 1992. Sexual size difference in Triturus newts: geographical variation in Yugoslav populations.Alytes, 10, 63-80.

Khatiwada, J. R., Wang, B., Ghimire, S., Vasudevan, K., Paudel, S. \& Jiang, J. 2015. A New Species of the Genus Tylototriton (Amphibia: Urodela: Salamandridae) from Eastern Himalaya. Asian Herpetological Research, 6,245-256.

Kieren, S., Sparreboom, M., Hochkirch, A. \& Veith, M. 2018. A biogeographic and ecological perspective to the evolution of reproductive behaviour in the family Salamandridae. Molecular Phylogenetics and Evolution,121, 98-109. https://doi.org/10.1016/j.ympev.2018.01.006

Kupfer, A. 2007. Sexual size dimorphism in amphibians: an overview. In: Fairbairn, D. J., Blanckenhorn, W. U. \& Székely, T. (eds.) Sex, size and gender roles: evolutionary studies of sexual size dimorphism. Oxford: Oxford University Press.

Kupfer, A., Nabhitabhata, J. \& Himstedt, W. 2004. Reproductive ecology of female caecilian amphibians (genus Ichthyophis ): a baseline study. Biological Journal of the Linnean Society, 83, 207-217.

Le, D. T., Nguyen, T. T., Nishikawa, K., Nguyen, S. L. H., Pham, A. V., Matsui, M., Bernardes, M. \& Nguyen, T. Q. 2015. A new species of Tylototriton Anderson, 1871 (Amphibia: Salamandridae) from northern Indochina. Current Herpetology, 34, 38-50.

Lindenfors, P., Gittleman, J. L. \& Jones, K. E. 2007. Sexual size dimorphism in mammals. In:Fairbairn, D. J., Blanckenhorn, W. U. \& Székely, T. (eds.) Sex, size and gender roles: evolutionary studies of sexual size dimorphism.Oxford: Oxford University Press.

Malmgren, J. C. \& Thollesson, M. 1999. Sexual size and shape dimorphism in two species of newts, Triturus cristatus and T. vulgaris (Caudata: Salamandridae). Journal of Zoology, 249, 127-136. https://doi.org/10.1017/s0952836999010018

Nishikawa, K., Khonsue, W., Pomchote, P. \& Matsui, M. 2013a. Two new species of Tylototriton from Thailand (amphibia: Urodela: Salamandridae). Zootaxa,3737, 261-279. https://doi.org/10.11646/zootaxa.3737.3.5

Nishikawa, K., Matsui, M. \& Nguyen, T. T. 2013b. A new species of Tylototriton from northern Vietnam (Amphibia: Urodela: Salamandridae). Current Herpetology,32, 34-49.

Nishikawa, K., Matsui, M. \& Rao, D. 2014. A new species of Tylototriton (Amphibia: Urodela: Salamandridae) from central Myanmar. The Natural History Bulletin of the Siam Society, 60, 2-2014.

Pasmans, F., Verbrugghe, E., Sparreboom, M., Xie, F. \& Martel, A. 2017. Adaptations of the amphibian egg and hatchling for terrestrial nesting in the Wenxian newt (Tylototriton wenxianensis ). 19th European Congress of Herpetology. Salzburg, Austria: SEH.

Perez, S. I., Bernal, V. \& Gonzalez, P. N. 2006. Differences between sliding semi-landmark methods in geometric morphometrics, with an application to human craniofacial and dental variation. Journal of Anatomy, 208, 769-784.

Phimmachak, S., Aowphol, A. \& Stuart, B. L. 2015a. Morphological and molecular variation in Tylototriton (Caudata: Salamandridae) in Laos, with description of a new species. Zootaxa, 4006, 285-310. https://doi.org/10.11646/zootaxa.4006.2.3

Phimmachak, S., Stuart, B. L. \& Aowphol, A. 2015b. Ecology and natural history of the Knobby Newt Tylototriton podichthys (Caudata: Salamandridae) in Laos.Raffles Bulletin of Zoology, 63, 389-400.

Pogoda, P. \& Kupfer, A. 2018. Flesh and bone: An integrative approach towards sexual size dimorphism of a terrestrial salamander (genus Salamandrina ). Journal of Morphology, 279, 1468-1479. https://doi.org/10.1002/jmor.20883 
Pogoda, P. \& Kupfer, A. 2020. Sexual shape dimorphism in the cranium and pelvic girdle of Northern spectacled salamanders, Salamandrina perspicillata, investigated via 3D geometric morphometrics. Salamandra, $56,113-122$.

Pogoda, P., Zuber, M., Baumbach, T., Schoch, R. R. \& Kupfer, A. 2020. Cranial shape evolution of extant and fossil crocodile newts and its relation to reproduction and ecology.Journal of Anatomy, 237, 285-300. https://doi.org/10.1111/joa.13201

Pomchote, P., Khonsue, W., Thammachoti, P., Hernandez, A., Peerachidacho, P., Suwannapoom, C., Onishi, Y. \& Nishikawa, K. 2020. A New Species of Tylototriton(Urodela: Salamandridae) from Nan Province, Northern Thailand. Tropical Natural History, 20, 144-161.

Poyarkov, N. A., Van Nguyen, T. \& Arkhipov, D. V. 2021. A new species of the genus Tylototriton (Amphibia, Caudata, Salamandridae) from central Vietnam. TAPROBANICA,10, 4-22. https://doi.org/10.47605/tapro.v10i1.244

Qian, L., Sun, X., Li, J., Guo, W., Pan, T., Kang, X., Wang, H., Jiang, J., Wu, J. \& Zhang, B. 2017. A New Species of the Genus Tylototriton (Amphibia: Urodela: Salamandridae) from the Southern Dabie Mountains in Anhui Province. Asian Herpetological Research, 8, 151-164.

R Development Core Team 2019. R: A Language and Environment for Statistical Computing. Vienna, Austria: R Foundation for Statistical Computing.

Reinhard, S. \& Kupfer, A. 2015. Sexual dimorphism in a French population of the marbled newt Triturus marmoratus (Urodela: Salamandridae). Salamandra,51, 121-128.

Reinhard, S., Renner, S. \& Kupfer, A. 2015. Sexual dimorphism and age of Mediterranean salamanders.Zoology, 118, 19-26. https://doi.org/10.1016/j.zool.2014.08.002

Rohlf, F. J. \& Slice, D. 1990. Extensions of the Procrustes method for the optimal superimposition of landmarks. Systematic Biology, 39, 40-59.

Romano, A., Bruni, G. \& Paoletti, C. 2009. Sexual dimorphism in the Italian endemic speciesSalamandrina perspicillata (Savi, 1821) and testing of a field method for sexing salamanders. Amphibia-Reptilia, 30,425434. https://doi.org/10.1163/156853809788795128

Salvador, A. \& Garcia-Paris, M. 1999. Pleurodeles waltl (Michahelles, 1830) - Rippenmolch.In: Grossenbacher, K. \& Thiesmeier, B. (eds.) Handbuch der Amphibien und Reptilien Europas. Band 4/I: Schwanzlurche (Urodela) I.Wiesbaden: Aula-Verlag.

Schauble, C. S. 2004. Variation in body size and sexual dimorphism across geographical and environmental space in the frogs Limnodynastes tasmaniensis and L. peronii . Biological Journal of the Linnean Society, $82,39-56$.

Schlager, S. 2017. Morpho and Rvcg-Shape Analysis in R. In: Zheng, G., Li, S. \& Szekely, G. (eds.) Statistical Shape and Deformation Analysis. London: Academic Press.

Schwarzkopf, L. 2005. Sexual dimorphism in body shape without sexual dimorphism in body size in water skinks (Eulamprus quoyii ). Herpetologica, 61,116-123.

Seglie, D., Roy, D. \& Giacoma, C. 2010. Sexual dimorphism and age structure in a population of Tylototriton verrucosus (Amphibia: Salamandridae) from the Himalayan Region. Copeia, 2010, 600-608.

Shen, Y., Jiang, J. \& Mo, X. 2012. A New Species of the Genus Tylototriton (Amphibia, Salamandridae) from Hunan, China. Asian Herpetological Research, 3,21-30.

Shetty, S. \& Shine, R. 2002. Sexual divergence in diets and morphology in Fijian sea snakes Laticauda colubrina (Laticaudinae). Austral Ecology, 27, 77-84.

Shine, R. 1979. Sexual selection and sexual dimorphism in the amphibia. Copeia, 1979,297-306. 
Shine, R. 1989. Ecological causes for the evolution of sexual dimorphism: a review of the evidence. The Quarterly Review of Biology, 64, 419-461. 10.1086/416458

Sparreboom, M. 2014.Salamanders of the Old World - The Salamanders of Europe, Asia and Northern Africa, p.431, Zeist, KNNV Publishing.

Stuart, B. L., Phimmachak, S., Sivongxay, N. \& Robichaud, W. G. 2010. A new species in theTylototriton asperrimus group (Caudata: Salamandridae) from central Laos. Zootaxa, 2650, 19-32.

Veith, M., Bogaerts, S., Pasmans, F. \& Kieren, S. 2018. The changing views on the evolutionary relationships of extant Salamandridae (Amphibia: Urodela). PLoS ONE,13, e0198237. https://doi.org/10.1371/journal.pone.0198237

Wang, B., Nishikawa, K., Matsui, M., Nguyen, T. Q., Xie, F., Li, C., Khatiwada, J. R., Zhang, B., Gong, D. \& Mo, Y. 2018. Phylogenetic surveys on the newt genus Tylototriton sensu lato (Salamandridae, Caudata) reveal cryptic diversity and novel diversification promoted by historical climatic shifts. PeerJ,6, e4384. https://doi.org/10.7717/peerj.4384

Yang, D., Jiang, J., Shen, Y. \& Fei, D. 2014. A new species of the genus Tylototriton (Urodela: Salamandridae) from northeastern Hunan Province, China. Asian Herpetological Research, 5, 1-11.

Zaw, T., Lay, P., Pawangkhanant, P., Gorin, V. \& Poyarkov, N. 2019. A new species of Crocodile Newt, genus Tylototriton (Amphibia, Caudata, Salamandridae) from the mountains of Kachin State, northern Myanmar. Zoological Research,40, 1-24. https://doi.org/10.24272/j.issn.2095-8137.2019.043

Zelditch, M. L., Swiderski, D. L. \& Sheets, H. D. 2012. Geometric morphometrics for biologists: a primer, p.488, Amsterdam, Academic Press.

\section{Tables}

Table 1: Results of a Procrustes ANOVA on 3D morphometric shape data of the humerus (a) and cranium (b) of crocodile newts (Echinotritonand Tylototriton ) to test for size-shape allometric relationship and shape differences between species and sex. Significant p-values are given in bold.

\begin{tabular}{|c|c|c|c|c|c|}
\hline & Df & SS & $\mathrm{F}$ & $\mathrm{Z}$ & $\mathrm{P}$ \\
\hline \multicolumn{6}{|l|}{$\begin{array}{l}\text { (a) Humerus } \\
\text { shape }\end{array}$} \\
\hline Size & 1 & 0.052 & 12.2422 & 5.1659 & $<0.0001$ \\
\hline Species & 8 & 0.52131 & 15.3404 & 13.493 & $<0.0001$ \\
\hline Sex & 1 & 0.052 & 12.2419 & 5.9927 & $<0.0001$ \\
\hline Size $\times$ Species & 8 & 0.06435 & 1.8935 & 3.6992 & 0.0002 \\
\hline Size $\times$ Sex & 1 & 0.0054 & 1.2712 & 0.7827 & 0.2173 \\
\hline Species $\times$ Sex & 8 & 0.0515 & 1.5155 & 2.6089 & 0.0058 \\
\hline $\begin{array}{l}\text { Size } \times \text { Species } \times \\
\text { Sex }\end{array}$ & 8 & 0.04296 & 1.2642 & 1.3734 & 0.0835 \\
\hline $\begin{array}{l}\text { Residuals } \\
\text { (b) Cranium } \\
\text { shape }\end{array}$ & 190 & 0.80709 & & & \\
\hline Size & 1 & 0.07857 & 24.2181 & 8.9468 & $<0.0001$ \\
\hline Species & 8 & 0.47169 & 18.1735 & 21.2585 & $<0.0001$ \\
\hline Sex & 1 & 0.00659 & 2.0323 & 2.6806 & 0.0037 \\
\hline Size $\times$ Species & 8 & 0.04496 & 1.7323 & 5.0003 & $<0.0001$ \\
\hline Size $\times$ Sex & 1 & 0.00314 & 0.9666 & 0.0356 & 0.4806 \\
\hline Species $\times$ Sex & 8 & 0.03238 & 1.2476 & 2.0453 & 0.0226 \\
\hline $\begin{array}{l}\text { Size } \times \text { Species } \times \\
\text { Sex }\end{array}$ & 8 & 0.03127 & 1.2049 & 1.5578 & 0.0603 \\
\hline
\end{tabular}




\begin{tabular}{llllll}
\hline & Df & SS & F & Z & P \\
\hline Residuals & 191 & 0.61967 & & & \\
\hline
\end{tabular}

Table 3: Results of a Procrustes ANOVA on 3D morphometric shape data of the humerus (a) and cranium (b) of crocodile newts (Echinotritonand Tylototriton) to test for SSD and mating mode as a potential selection force for different SSD-patterns between species (c, d). Significant p-values are given in bold.

\begin{tabular}{|c|c|c|c|c|c|}
\hline & Df & SS & $\mathrm{F}$ & Z & $\mathrm{P}$ \\
\hline \multicolumn{6}{|l|}{$\begin{array}{l}\text { (a) Humerus } \\
\text { size }\end{array}$} \\
\hline Species & 8 & 2.0433 & 38.2325 & 6.8966 & $<0.0001$ \\
\hline Sex & 1 & 0.193 & 28.8894 & 2.0828 & $<0.0001$ \\
\hline Species × Sex & 8 & 0.1218 & 2.2799 & 1.7555 & 0.0228 \\
\hline $\begin{array}{l}\text { Residuals } \\
\text { (b) Cranium } \\
\text { size }\end{array}$ & 208 & 1.3895 & & & \\
\hline Species & 8 & 2805.8 & 38.9619 & 6.9389 & $<0.0001$ \\
\hline Sex & 1 & 813.7 & 90.3948 & 2.5681 & $<0.0001$ \\
\hline Species $\times$ Sex & 8 & 164.1 & 2.2787 & 1.7348 & 0.0249 \\
\hline $\begin{array}{l}\text { Residuals } \\
\text { (c) Humerus } \\
\text { size with } \\
\text { mating mode }\end{array}$ & 209 & 1881.3 & & & \\
\hline Sex & 1 & 0.1617 & 10.2769 & 1.62461 & 0.0018 \\
\hline Mating mode & 1 & 0.0325 & 2.0677 & 0.91544 & 0.1491 \\
\hline $\begin{array}{l}\text { Sex } \times \text { Mating } \\
\text { mode }\end{array}$ & 1 & 0.0608 & 3.8643 & 1.18851 & 0.053 \\
\hline $\begin{array}{l}\text { Residuals } \\
\text { (d) Cranium } \\
\text { size with } \\
\text { mating mode }\end{array}$ & 222 & 3.4927 & & & \\
\hline Sex & 1 & 1045.9 & 55.5155 & 2.3744 & $<0.0001$ \\
\hline Mating mode & 1 & 275.3 & 14.6103 & 1.7744 & $<0.0001$ \\
\hline $\begin{array}{l}\text { Sex } \times \text { Mating } \\
\text { mode }\end{array}$ & 1 & 142.5 & 7.5664 & 1.4634 & 0.0064 \\
\hline Residuals & 223 & 4201.2 & & & \\
\hline
\end{tabular}

\section{Figures}

Figure 1: Definition of three-dimensional fixed landmarks (red) and semi-landmarks (yellow) set on the cranium and humerus of crocodile newts (genera Tylototriton and Echinotriton) for the geometric morphometrics analysis of SD. Shown are the cranium of SMF1134 (male T. verrucosus ) and humerus of ZSM0830-2012 (female T. himalayanus) derived from mCT data.

Figure 2: Morphospace of humerus shape of crocodile newts (Tylototriton spp. and Echinotriton andersoni ) build by the first PC axes of a PCA of 56 GPA-aligned 3D landmarks. Shape changes at the minimum and maximum of each axis are presented as TPS-deformed grids from the mean shape. Colour code correspond to setting in subsequent figures. 
Figure 3: Morphospace of cranial shape of crocodile newts (Tylototriton spp. and Echinotriton andersoni ) build by the first PC axes of a PCA of 45 GPA-aligned 3D landmarks. Shape changes at the minimum and maximum of each axis are presented as TPS-deformed grids from the mean shape. For colour coding see Figure 2 .

Figure 4: Unique allometry in humerus (a) and cranium (b) shape of nine species of crocodile newts (Tylototriton spp. andEchinotriton andersoni) estimated by multivariate regression. Shape changes to the mean shape are presented as TPS-deformation grids for the largest (upper) and smallest (lower) fitted value. For colour coding see Figure 2 .

Figure 5: Common allometry in humerus (a) and cranium (b) shape of crocodile newts (Tylototriton spp. and Echinotriton andersoni) of females and males estimated by multivariate regression. Shape changes to the mean shape are presented as TPS-deformation grids for the largest (upper) and smallest (lower) fitted value. The shape changes for the humerus are magnified by the factor of three. For colour coding see Figure 2 .

Figure 6: TPS-deformation grids from the mean shape (reference) to the different mating modes (target: circle dance, amplexus) of crocodile newts (Tylototriton spp. and Echinotriton andersoni) of the humerus (upper rows) and cranial shape (lower rows). The shape changes are magnified by the factor of three.

Figure 7: Trajectory analysis of SD in humerus shape of crocodile newt (Tylototriton spp. and Echinotriton andersoni ) for whole data set (upper left) and for mean shape predictions for each sex and species (upper right). TPS-deformation grids of two exemplary species with different trajectories are illustrated in the lower rows. Those trajectories are marked in the upper graphs by an arrow indicating the direction from male to female. Shape changes for those are shown from male (reference) to females (target). The shape changes are magnified by the factor of two. For colour coding see Figure 2.

Figure 8: Trajectory analysis of SD in cranial shape of crocodile newts (Tylototriton spp. and Echinotriton andersoni ) for whole data set (upper left) and for mean shape predictions for each sex and species (upper right). In the lower row TPS-deformation grids of two exemplary species with different trajectories are illustrated. Those trajectories are marked in the upper graphs by an arrow indicating their directions. Shape changes for those are shown from male (reference) to females (target). The shape changes are magnified by the factor of three. For colour coding see Figure 2.

Figure 9: TPS-deformation grids from the mean shape (reference) to male and female shapes (target) of Tylototriton himalayanus (amplexus) and T. kweichowensis (circle dancer) for the humerus (upper rows) and cranium (lower rows). The selected species represent different sexual dimorphism-trajectories and different mating modes. The shape changes are magnified by the factor of two for the humerus and by the factor of three for the cranium.

Data accessibility: Raw-data (3D geometric morphometric landmarks) is accessible under https://www.doi.org/10.6084/m9.figshare.14381315 [upon acceptance].

Competing interests: The authors have no conflicts of interest to declare.

Author contributions: PP - study design, specimen loans, CT-scanning, data collection, data analysis, data interpretation, drafting manuscript. MZ - CT-scanning, data collection. TB - CT-scanning. AK study design, specimen loans, supervision. All authors edited and approved the manuscript draft.

Acknowledgments : Collection-based research of PP was partly funded by the Wilhelm-Peters-Fonds of the Deutsche Gesellschaft für Herpetologie und Terrarienkunde e.V. (DGHT), funding number WP-01/2017. Further, PP received funding for travel costs by the PROMOS program of the DAAD and the Reinhold-undMaria-Teufel-Stiftung, Tuttlingen. We thank all curators and collection managers of natural history museums for granting access to salamanders in their care: Raffael Ernst and Markus Auer (MTKD, Dresden), Gunter Köhler and Linda Acker (SMF, Frankfurt a. Main), Mark-Oliver Rödel and Frank Tillak (ZMB, Berlin), Frank Glaw and Michael Franzen (ZSM, Munich), Dennis Rödder and Morris Flecks (ZFMK, Bonn), Silke 
Schweiger and Georg Gassner (NHMW, Vienna), Annemarie Ohler (MNHN, Paris), Lauren Scheinberg (CAS, Berkeley, CA) and Kevin de Queiroz and Esther Langan (USNM, Suitland, MD). The geomorph-community is thanked for much help with the R script. Further thanks go to Katharina Foerster and James Nebelsick being always a source of good scientific advice. This work represents a contribution to obtain the PhD degree of PP at the University of Tuebingen.

\section{Appendix}

Table A1: Pairwise comparison of trajectories of SShD's in species of crocodile newts (Echinotriton and Tylototriton ) on humerus (a) and cranium shape (b). P-values below 0.1 are given in bold.

\begin{tabular}{|c|c|c|c|c|}
\hline Species pairs & $\mathbf{r}$ & angle & $\mathbf{Z}$ & $\operatorname{Pr}$ \\
\hline \multicolumn{5}{|c|}{ (a) Humerus shape } \\
\hline AND:ASP & -0.46682813 & 117.8286 & 1.42714827 & 0.0746 \\
\hline AND:HIM & -0.0120951 & 90.69301 & -0.00512674 & 0.5012 \\
\hline AND:KWE & -0.13387113 & 97.69335 & 0.73897297 & 0.2311 \\
\hline AND:SHA & 0.05446646 & 86.87776 & 0.056926 & 0.4666 \\
\hline AND:SHJ & 0.04006747 & 87.70369 & -0.05172983 & 0.5213 \\
\hline AND:TAL & 0.53610158 & 57.58135 & -1.76256895 & 0.9657 \\
\hline AND:UYE & 0.36209305 & 68.77121 & -0.7127958 & 0.7529 \\
\hline AND:VER & 0.07283752 & 85.82302 & -0.30812571 & 0.6189 \\
\hline ASP:HIM & 0.14873708 & 81.44625 & -0.66479591 & 0.7401 \\
\hline ASP:KWE & 0.25241557 & 75.3795 & -0.84296483 & 0.7903 \\
\hline ASP:SHA & -0.01299515 & 90.74459 & 0.75814302 & 0.2282 \\
\hline ASP:SHJ & -0.04465795 & 92.55956 & -0.46166446 & 0.6804 \\
\hline ASP:TAL & -0.52673433 & 121.78507 & 1.87861716 & 0.0283 \\
\hline ASP:UYE & -0.10685649 & 96.13414 & -0.37192933 & 0.6473 \\
\hline ASP:VER & 0.00894002 & 89.48777 & -0.29657821 & 0.6105 \\
\hline HIM:KWE & -0.19172995 & 101.05376 & 1.64203571 & 0.0565 \\
\hline HIM:SHA & -0.26771584 & 105.52839 & 1.47485254 & 0.0758 \\
\hline HIM:SHJ & -0.20699712 & 101.94643 & 1.36848011 & 0.0971 \\
\hline HIM:TAL & -0.15937028 & 99.17035 & 1.17140961 & 0.1262 \\
\hline HIM:UYE & 0.4003387 & 66.40065 & -0.44493701 & 0.6487 \\
\hline HIM:VER & 0.00412744 & 89.76351 & 0.71191072 & 0.2429 \\
\hline KWE:SHA & -0.0088412 & 90.50657 & 1.09575509 & 0.1425 \\
\hline KWE:SHJ & 0.61019192 & 52.39662 & -0.74910418 & 0.7647 \\
\hline KWE:TAL & -0.22281803 & 102.8746 & 1.34217213 & 0.0978 \\
\hline KWE:UYE & 0.36216274 & 68.76692 & 0.24327653 & 0.3818 \\
\hline KWE:VER & 0.54550481 & 56.94083 & -0.13251308 & 0.5195 \\
\hline SHA:SHJ & -0.4629657 & 117.57864 & 1.42755566 & 0.0736 \\
\hline SHA:TAL & 0.14496272 & 81.66488 & -0.03093918 & 0.4975 \\
\hline SHA:UYE & -0.32654714 & 109.05933 & 1.38385114 & 0.0873 \\
\hline SHA:VER & -0.19935571 & 101.49929 & 1.27296807 & 0.1081 \\
\hline SHJ:TAL & 0.06429223 & 86.31378 & 0.16182486 & 0.4255 \\
\hline SHJ:UYE & 0.49968769 & 60.02066 & 0.1341753 & 0.423 \\
\hline SHJ:VER & 0.74251775 & 42.05367 & -0.83387732 & 0.7875 \\
\hline TAL:UYE & 0.1775251 & 79.77436 & 0.06487828 & 0.4555 \\
\hline TAL:VER & 0.06432208 & 86.31207 & 0.41444624 & 0.3328 \\
\hline UYE:VER & 0.63670485 & 50.45345 & -0.81725357 & 0.787 \\
\hline
\end{tabular}

(b) Cranium shape 


\begin{tabular}{lllll}
\hline Species pairs & $\mathbf{r}$ & angle & $\mathbf{Z}$ & $\mathbf{P r}$ \\
\hline AND:ASP & -0.1261636 & 97.24796 & 0.0775665 & 0.4723 \\
AND:HIM & -0.30251033 & 107.60844 & 1.09158763 & 0.1389 \\
AND:KWE & 0.29503507 & 72.84036 & -0.69800575 & 0.7466 \\
AND:SHA & 0.07864737 & 85.48918 & -0.5373217 & 0.7013 \\
AND:SHJ & -0.37974107 & 112.31765 & 1.46829175 & $\mathbf{0 . 0 6 8 3}$ \\
AND:TAL & -0.1690142 & 99.73051 & 0.17923985 & 0.4358 \\
AND:UYE & 0.08458317 & 85.14794 & 0.02649171 & 0.4898 \\
AND:VER & 0.19977892 & 78.47597 & -0.78562098 & 0.7842 \\
ASP:HIM & 0.05401751 & 86.90352 & -0.06967234 & 0.5258 \\
ASP:KWE & -0.03602013 & 92.06425 & 0.16934995 & 0.4337 \\
ASP:SHA & 0.05470757 & 86.86392 & -0.39646266 & 0.6555 \\
ASP:SHJ & 0.1635958 & 80.58433 & -1.11524936 & 0.8643 \\
ASP:TAL & -0.06271244 & 93.59552 & 0.50957328 & 0.3016 \\
ASP:UYE & -0.03213558 & 91.84155 & -0.75919772 & 0.7778 \\
ASP:VER & -0.06224594 & 93.56874 & -0.38105796 & 0.6573 \\
HIM:KWE & -0.41805572 & 114.7119 & 2.29509464 & $\mathbf{0 . 0 0 9}$ \\
HIM:SHA & -0.1168173 & 96.70846 & 0.59568357 & 0.278 \\
HIM:SHJ & 0.28526743 & 73.42516 & -0.66344354 & 0.7422 \\
HIM:TAL & 0.52602148 & 58.26297 & -1.85361949 & 0.9726 \\
HIM:UYE & -0.28356754 & 106.47324 & 0.8218822 & 0.2097 \\
HIM:VER & 0.07493355 & 85.7026 & -0.17084595 & 0.5734 \\
KWE:SHA & -0.11479272 & 96.59167 & 0.0104961 & 0.4976 \\
KWE:SHJ & -0.31540426 & 108.38522 & 1.29039027 & $\mathbf{0 . 0 9 7 3}$ \\
KWE:TAL & -0.20141995 & 101.62001 & 0.61955319 & 0.2755 \\
KWE:UYE & -0.03372357 & 91.93258 & 0.761438 & 0.2293 \\
KWE:VER & -0.07563739 & 94.33785 & 0.08850095 & 0.4692 \\
SHA:SHJ & 0.13243547 & 82.38965 & 0.22839201 & 0.4026 \\
SHA:TAL & 0.23361424 & 76.49005 & -0.88320676 & 0.8091 \\
SHA:UYE & -0.01467623 & 90.84092 & -0.33849917 & 0.6335 \\
SHA:VER & 0.19220274 & 78.91864 & -0.73949528 & 0.7674 \\
SHJ:TAL & 0.22580437 & 76.94982 & -0.06604023 & 0.5206 \\
SHJ:UYE & 0.16990833 & 80.21751 & -1.01623994 & 0.8425 \\
SHJ:VER & -0.15157714 & 98.71834 & 2.21616912 & $\mathbf{0 . 0 1 5 1}$ \\
TAL:UYE & -0.03780691 & 92.16669 & 0.38374482 & 0.3481 \\
TAL:VER & 0.20593045 & 78.11603 & -1.0360533 & 0.8494 \\
UYE:VER & 0.02429858 & 88.60766 & 0.30094108 & 0.375 \\
\hline & & & & \\
& & & & \\
& & & &
\end{tabular}



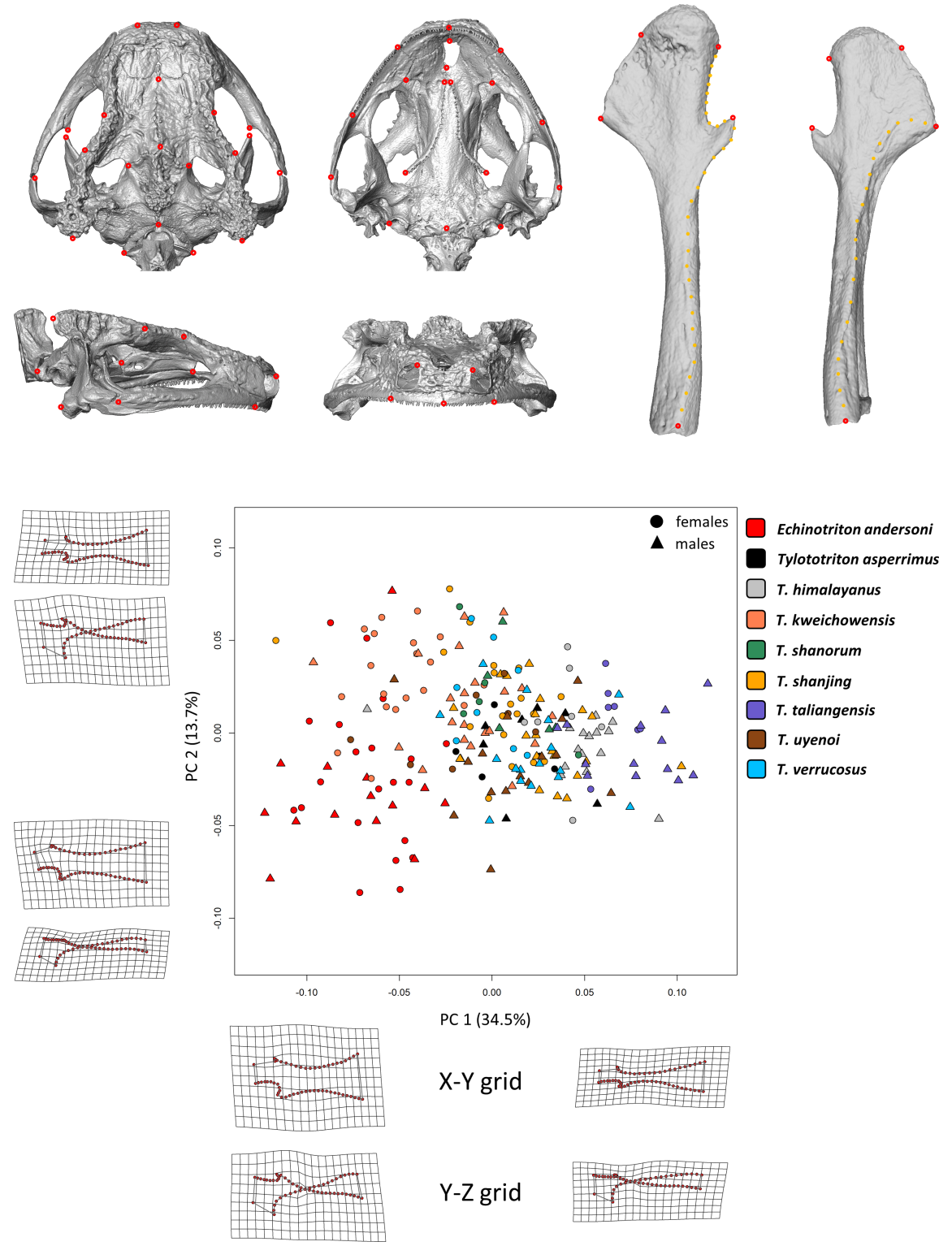

$$
\text { . }
$$



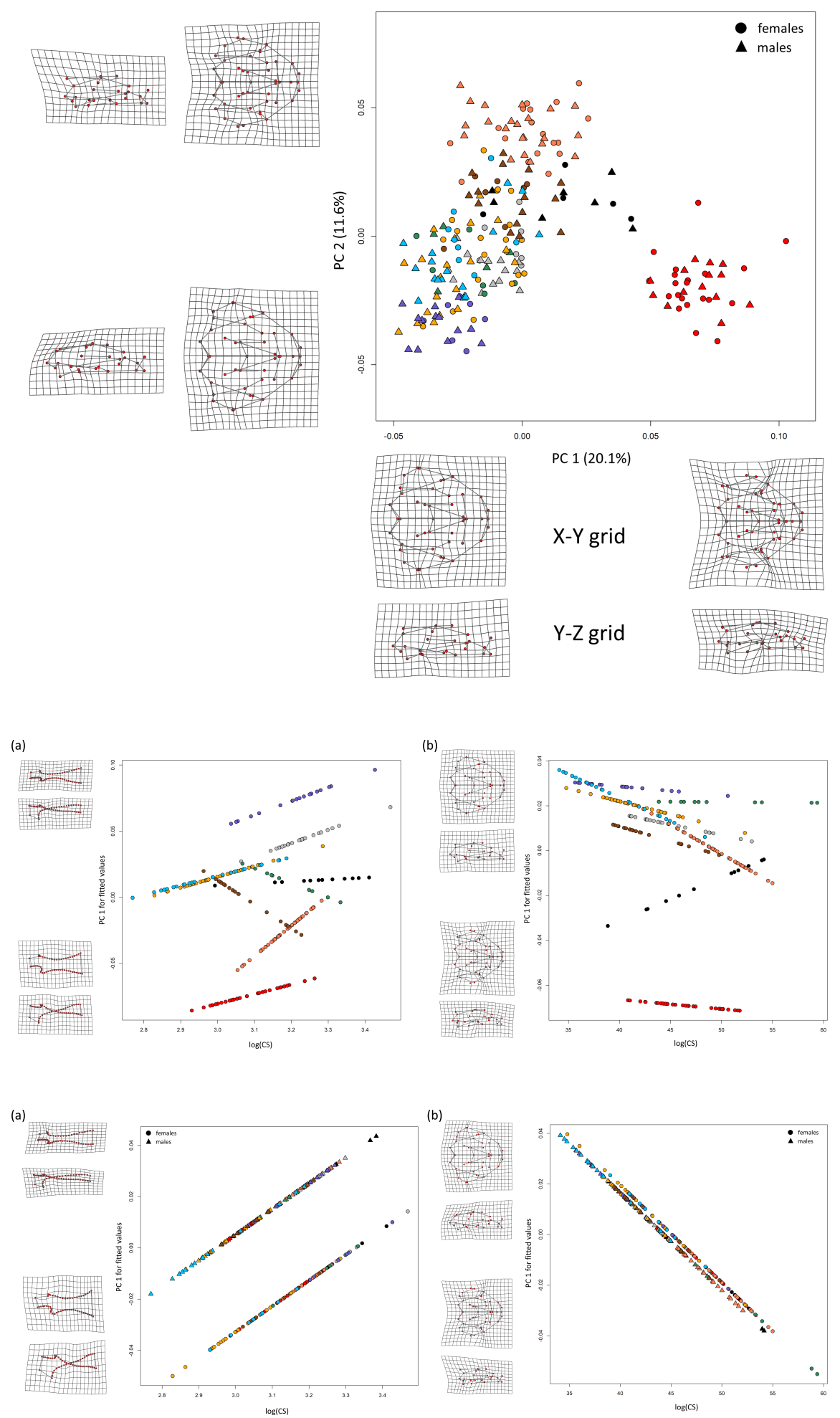

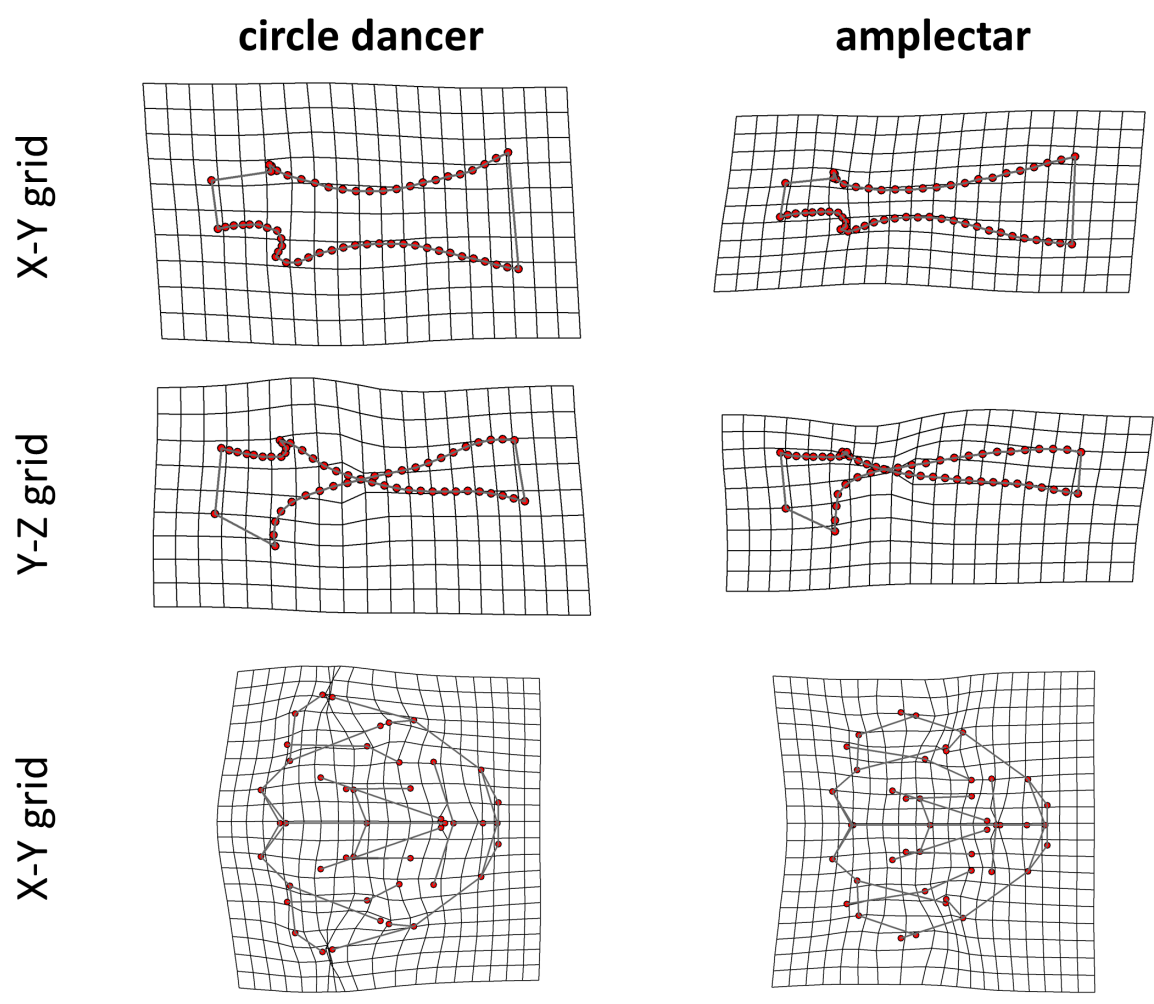

$\frac{7}{2}$
$\frac{1}{60}$
$\frac{1}{>}$
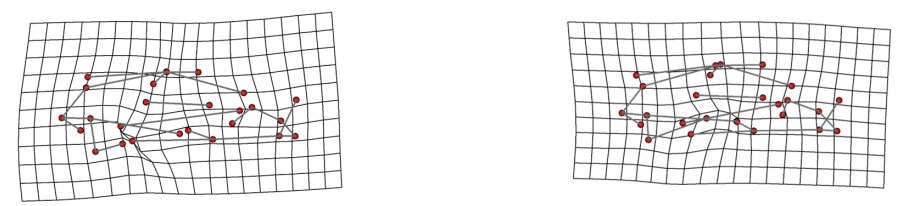

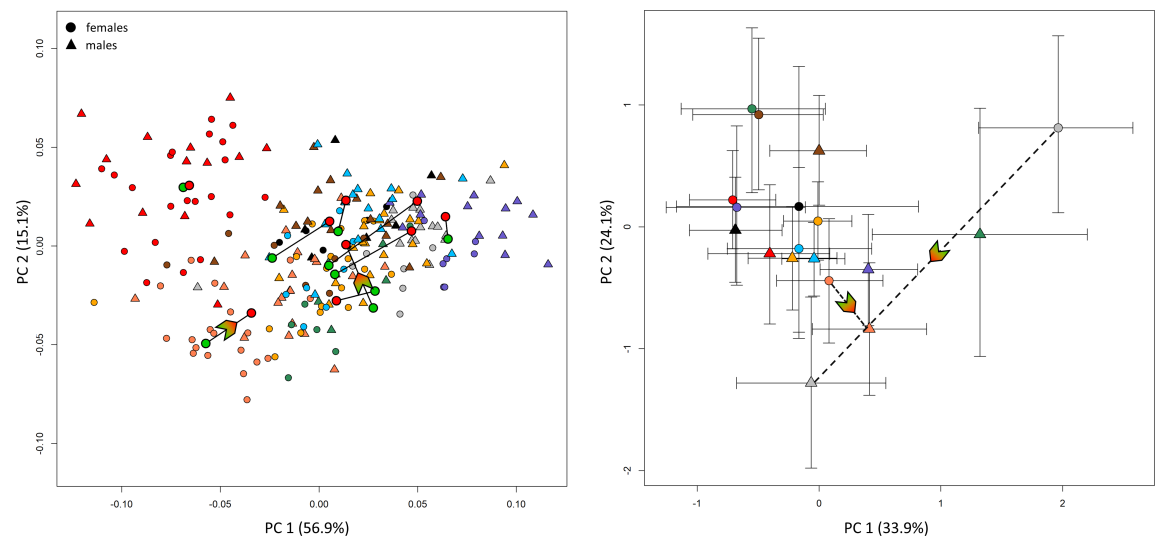

T. himalayanus
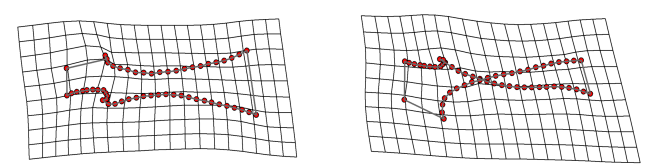

T. kweichowensis
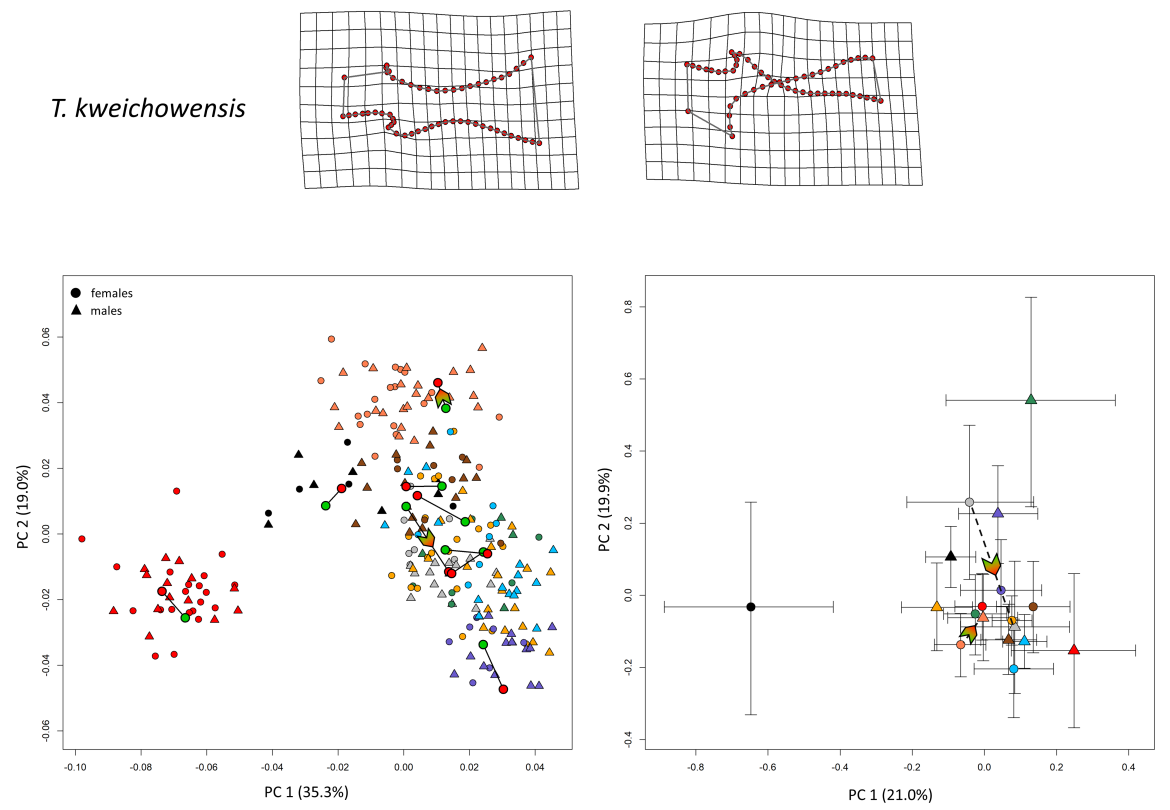

T. himalayanus

T. kweichowensis
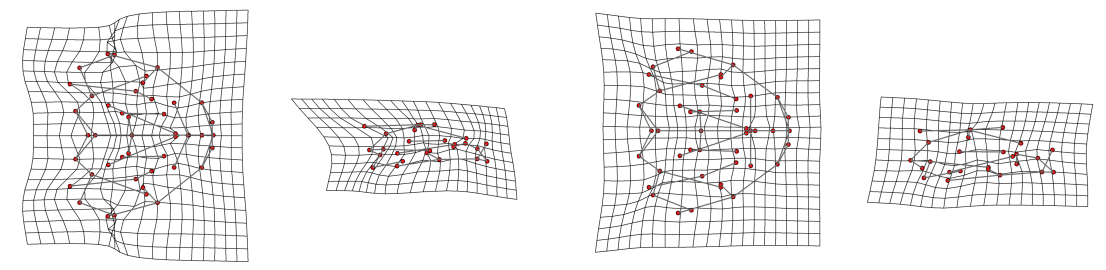
T. himalayanus

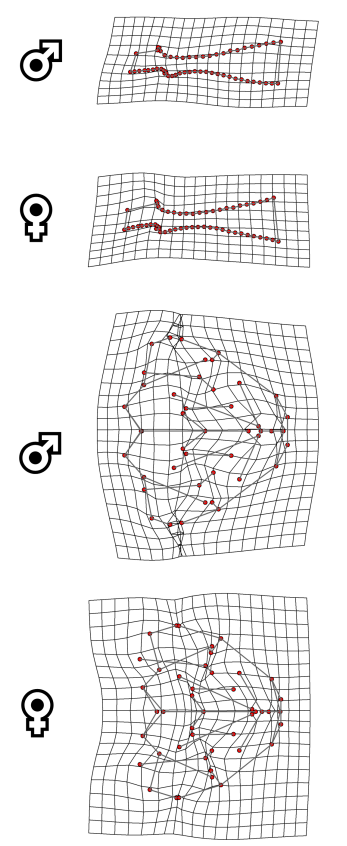

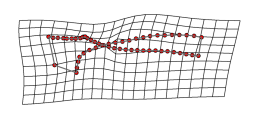
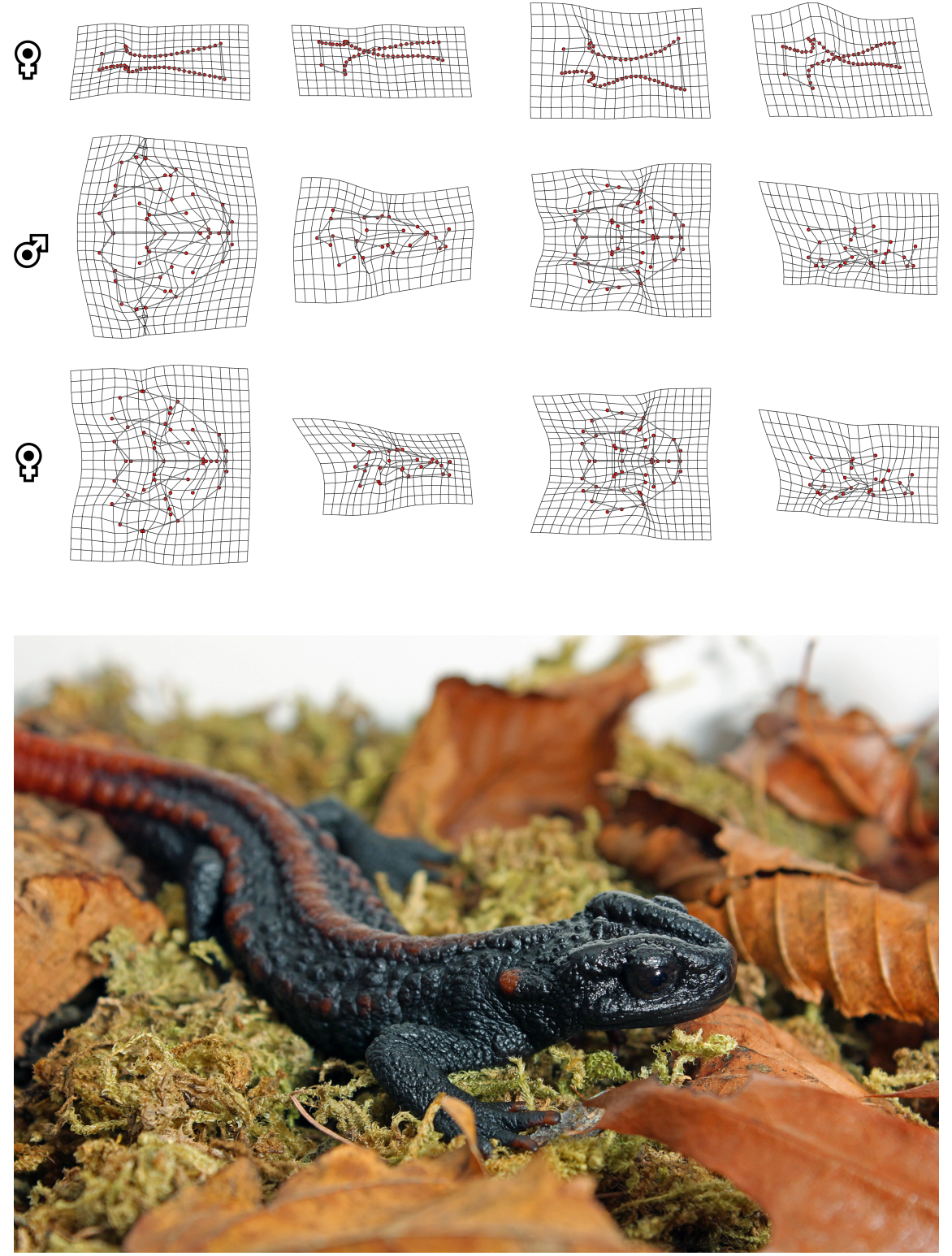